\title{
Editor's Preface
}

Since the journal's inception, contributions for topical issues often originated from the annual International Workshop for History and Philosophy of Science that is jointly organized by the Cohn Institute for History and Philosophy of Science and Ideas, Tel-Aviv University; the Edelstein Center of the Hebrew University; and the Van Leer Jerusalem Institute. The editors of this journal have occasionally asked the organizers of such meetings to become guest editors for topical issues of Science in Context.

In May 2001 the International Workshop was organized by Sabetai Unguru and myself. This workshop was entitled "History of Mathematics in the Last 25 Years. New Departures, New Questions, New Ideas." Its sessions were conceived as an opportunity to "take stock of new developments in the history of mathematics" whose role has changed over the last quarter century from an appendage to the study and, primarily, teaching of mathematics, to an independent historical discipline.

For the Israeli community of researchers in history and philosophy of science, who routinely organize these meetings, the choice of the history of mathematics as the topic for 2001 was, as in previous years, rather incidental. If there was any reason for this particular choice, it was that no such workshop had yet been devoted to a field that drew high interest in Israel.

As it happened, an additional reason for attending the meeting soon became apparent as the historians of mathematics who were invited from Israel and abroad saw the workshop as a special opportunity to assess from their own points of view the contributions of Sabetai Unguru to the discipline. Sabetai had just retired after many years of influential scholarly activity. His seminal and controversial paper, "On the Need to Rewrite the History of Greek Mathematics," had been published in 1975, that is, just twenty-five years before the invitations were issued.

Most speakers - beginning with Gideon Freudenthal from Tel Aviv University who welcomed the guests at the opening session, and continuing with the various scholars who presented original contributions - used the opportunity to honor Sabetai in some way or other. Independently of the organizers' initial conception, the workshop had thus turned into a meeting that was more than merely the encounter of invited speakers and discussants. In his unequivocally straightforward way, Sabetai Unguru made it clear that he was quite displeased with the particular turn our initial conception had undergone. Others, including myself, enjoyed this unintended turn of events.

The wealth and quality of the contributions presented at the meeting led the editors of Science in Context to organize the material into two separate topical issues, one on ancient and one on modern mathematics. Needless to say, the contributions were planned, designed, and refereed as in any other issue of the journal. We have also been fortunate that Reviel Netz agreed to serve as guest editor for the first issue. The 
outcome has indeed been rewarding. This first part is devoted to the history of ancient mathematics; the second part is due to appear in the spring of 2004.

The essentials of Sabetai Unguru's contribution to recent historiography of mathematics, and specifically to that of Greek mathematics, are explained, discussed, and assessed in the works gathered here. This is not the place to add any further comments to them. This is indeed the place, however, to pay a small tribute to those unique traits of Sabetai's personality that have made him a cherished friend, a respected colleague, and an honored teacher, for all those who have come to know him over the years. Sabetai Unguru is a "collector's item," a model that is not being produced anymore these days. It has been both a pleasure and an honor for me to actively participate in this project that has now materialized as a regular issue of Science in Context.

Leo Corry 